\title{
Quantitation of serum free light chains does not compensate for serum immunofixation only when screening for monoclonal gammopathies
}

\author{
Klas Böer* and Thomas Deufel \\ Institut für Klinische Chemie und \\ Laboratoriumsdiagnostik, Friedrlich-Schiller \\ University Jena, Jena, Germany
}

\begin{abstract}
Background: Detection of plasma cell dyscrasias (PCD) requires screening of serum and urine for monoclonal proteins. Several studies have demonstrated increased sensitivity and specificity when measurement of serum free light chain (SFLC) is part of the screening protocol. In addition, omission of immunofixation (IFE) in the standard work-up that includes SFLC assay has been proposed. This study attempts to define the role of the SFLC assay in a screening strategy limited to serum only. It compares outcomes to a serum-only screening strategy that omits serum IFE.
\end{abstract}

Methods: Serum from 691 patients was analysed for the presence of monoclonal protein using standard serum IFE, serum protein electrophoresis (SPE) and measurement of SFLC. Data were analysed retrospectively.

Results: Specificity and sensitivity of abnormal SFLCratios for the detection of monoclonal protein using IFE were $96 \%$ and $41 \%$, respectively. Eighteen patients with negative monospecific and Bence Jones IFE, but abnormal SFLC-ratios were identified. In most cases, this could be attributed to kidney and inflammatory disease or haematological disorders. In four cases, this resulted in further diagnostic investigation and light chain disease was later detected in two cases. Light chain disease was confirmed in one case but not confirmed in the other patient. In 14 patients, Bence Jones IFE was negative, although the concentrations of SFLC suggested the presence of monoclonal Bence Jones protein at concentrations detectable by IFE. Thus, either the anti-serum failed at detection, there was polymerisation of the free light chains or the SFLC assay overestimated protein concentrations. Simulating a work-up that included IFE only if abnormalities were detected by SPE or the SFLC assay would have resulted in $26 \%$ fewer IFEs being performed, but three patients with monoclonal proteins by IFE would have been missed.

Conclusions: Abnormal SFLC concentrations are neither sensitive nor specific for the detection of

*Corresponding author: Klas Böer, Institut für Klinische Chemie und Laboratoriumsdiagnostik, Friedrlich-Schiller University Jena, 07740 Jena, Germany

E-mail: kboeer@med.uni-jena.de

Received February 2, 2009; accepted June 19, 2009 monoclonal proteins by IFE. Not all PCD are accompanied by excessive production of SFLC, and several other conditions, such as renal disease are associated with increased SFLC concentrations. An abnormal SFLC-ratio is a specific marker for PCD, and occurs primarily in patients with haematological disease. If renal and inflammatory diseases are excluded, this should prompt further diagnostic investigation. Screening of serum without performing an IFE as a standard procedure leads to a reduction of sensitivity when compared to screening of serum that includes IFE.

Clin Chem Lab Med 2009;47:1109-15.

Keywords: monoclonal gammopathies; screening; serum free light chain.

\section{Introduction}

Detection and monitoring of patients with plasma cell dyscrasias (PCD), such as intact immunoglobulin myeloma (IIMM), non-secretory myeloma (NSMM), light-chain multiple myeloma (LCMM) and AL amyloidosis $(A L)$ requires laborious work-up including serum protein electrophoresis (SPE) and immunofixation (IFE) of serum and urine $(1,2)$. Although this procedure allows detection of LCMM, quantitation of serum free light chain (SFLC) was difficult and prone to error, especially due to non-specific binding of intact immunoglobulins (3). Recently, a turbidimetric assay became available allowing for more specific detection and quantitation of SFLC in serum and urine (4).

Quantitation of SFLC is recommended for patients with multiple myeloma (5), and patients with $A L$ (6) because it appears to offer advantages in diagnosis and follow-up. However, there is no consensus on a safe and cost effective strategy to screen patients with suspected PCD (7-15). Recently, it has been suggested to replace screening of urine for FLC by quantitation of FLC in serum as the standard screening procedure; reducing turn-around time but increasing costs $(7,8,12,13)$. Some have even suggested omitting IFE $(11,14)$. Although screening of urine and serum remains the gold standard, offering the highest sensitivity and specificity for the detection of monoclonal gammopathy (16), screening of serum only is common practise because collection of urine is often forgotten. For example, recent studies showed that only $35 \%-40 \%$ of serum samples were accompanied by urine samples $(7,17)$. Therefore, establishing a standardised screening procedure that depends on 
urine IFE is difficult. In addition, handling one sample only is cost- and time-saving, and reduces labour input (7). We chose a PCD screening strategy using serum only, and performed SPE, screening IFE with pentavalent anti-serum and, if positive, a monospecific IFE. We attempted to elicit the role of the "Freelite" SFLC assay in this modified work-up. Sera from two of three patients, who were later diagnosed with PCD and who were positive by the SFLC assay but negative by Bence Jones IFE, were studied more thoroughly.

In a high-throughput laboratory environment, reduction of hands-on-time by eliminating manual methods from the standard workflow is desirable. In the case of PCD screening, this applies to the standard serum IFE, even though it is considered to be the gold standard. This approach has been tested recently $(11,14$, 16). In one report, it was found to be suitable for PCD screening, but except for these studies there has been no validation of this approach (11). Therefore, the use of a screening strategy that omits IFE and is similar to that suggested previously was evaluated in a hospital population.

\section{Materials and methods}

\section{Patient population}

We retrospectively reviewed all data from 691 patient serum samples that were initially screened for suspected monoclonal gammopathy (monoclonal screening programme) between August 2006 and September 2007 in a hospital population (requesting wards: 190 haematology/oncology, 113 nephrology, 99 neurology, 38 gastroenterology, 37 cardiology, 30 rheumatology, 30 dermatology, 23 endrocrinology, 21 infectious diseases, 110 other patients). Mean age of the patients was 65 years [standard deviation (SD): 14.4 years] with 313 females and 378 males. This population resembles a setting in which samples from unselected patients with clinical suspicion of monoclonal gammopathy are screened. It includes patients with other diseases that are known to influence SFLC concentrations. For patients sampled repeatedly in the monoclonal gammopathy screening programme during this time, only the first sample was included in the analysis. On request from the ordering physician, the laboratory offers SPE which is evaluated for the presence of Mprotein bands that is independent of the monoclonal screening programme (see standard work-up). In addition to the 691 patients who were screened in the monoclonal screening programme, 10,818 SPEs were performed for other patients during the study period.

\section{Technical procedures}

SPE was performed using capillary zone electrophoresis (Paragon capillary zone electrophoresis 2000; Beckman Coulter, Krefeld, Germany). IFE was performed using the Hydragel 4 IF Kit (Sebia, Fulda, Germany) with either pentavalent antiserum (Sebia) or monospecific IFE (specificity: $\kappa$ free and bound light chains, $\lambda$ free and bound light chains, $\alpha, \gamma$ and $\mu$ heavy chains). Bence Jones IFE in serum was performed using the Hydragel Bence Jones Kit (Sebia). The manufacturer of the assay states that sensitivity of the Bence Jones IFE is at least $50 \mathrm{mg} / \mathrm{L}$ in urine, or $150 \mathrm{mg} / \mathrm{L}$ in serum since a 1:3 dilution is performed to minimise background for any monoclonal $\kappa-$ or $\lambda$-FLC. However, it may be lower for individual monoclonal $\kappa^{-}$or $\lambda$-FLC. Therefore, a general detection limit of $150 \mathrm{mg} / \mathrm{L}$ in serum was assumed in this analysis. $\kappa$ - and $\lambda$-SFLC were quantified using the "Freelite" assay (The Binding Site, Schwetzingen, Germany) with the BNII (Dade Behring, Marburg, Germany) nephelometric analyser according to the manufacturer's instructions. Reference intervals were $<19.4 \mathrm{mg} / \mathrm{L}$ for $\mathrm{\kappa}$-SFLC, $<26.3$ for $\lambda$-SFLC and 0.26-1.65 for the SFLC-ratio. Because there is no pathology associated with decreased SFLC-concentrations we used only an upper reference limit. All samples were initially measured at a 1:100 dilution to minimise re-runs, and SFLC concentrations below $10 \mathrm{mg} / \mathrm{L}$ were reported as $<10 \mathrm{mg} / \mathrm{L}$. We modified the manufacturer's recommendations and re-runs were performed at dilutions of 1:2000, $1: 40,000$ and $1: 160,000$ dilutions to minimise reagent consumption.

Imprecision of the assay was $11.6 \%$ ( $\lambda$-SFLC, mean: $31.1 \mathrm{mg} / \mathrm{L}$ ), $5.2 \%$ ( $\lambda$-SFLC; mean: $56.6 \mathrm{mg} / \mathrm{L}$ ), 7.9\% (к-SFLC; mean: $15.9 \mathrm{mg} / \mathrm{L}$ ), $7.3 \%$ ( $\mathrm{K}-\mathrm{SFLC}$; mean: $29.3 \mathrm{mg} / \mathrm{L}$ ), $12.5 \%$ (SFLC-ratio low concentrations; mean: 0.52 ) and $8.1 \%$ (SFLCratio high concentrations; mean: 0.52 ).

\section{Standard work-up}

The standard work-up included SPE, IFE with pentavalent antiserum and analysis of $\kappa$ - and $\lambda$-SFLC. SPE was performed to provide follow-up for the requesting physician. If screening with pentavalent antiserum indicated the presence of monoclonal protein, monospecific IFE (for specificities, see above) was performed.

If using monospecific IFE a monoclonal band against $\mathrm{k}$ and/or $\lambda$ without associated heavy chain was detected, a Bence Jones protein or a monoclonal $\lg D$ or $\lg E$ was assumed. Because Bence Jones proteins are more common, a Bence Jones IFE was performed first. If there was no evidence of the presence of Bence Jones protein in peripheral blood, further testing against $\Delta$ and $\varepsilon$ heavy chains using IFE was performed.

\section{Data analysis}

Patient clinical information was obtained from the hospital information system. Calculations were performed using Analyse-it (Analyse-it Software, Ltd., Leeds, UK) and Excel (Microsoft, Unterschleissheim, Germany).

\section{Results}

\section{Test performance of increased $\kappa-/ \lambda$-SFLC concentrations and SFLC-ratio for the detection of monoclonal protein by IFE}

Sensitivity and specificity for increased $\kappa$ - or $\lambda$-SFLC concentrations, or an abnormal ratio for the detection of monoclonal protein by IFE indicating PCD [monoclonal gammopathy of undetermined significance (MGUS), multiple myeloma, Waldenström macroglobulinaemia, monoclonal light-chain $(\mathrm{AL})$ amyloidosis] was evaluated in 690 patients (one patient with IgA but no detectable light chain by IFE was excluded). The patients included 196 (30\%) with intact immunoglobulins and $18(2.6 \%)$ patients with Bence Jones protein as diagnosed with Bence Jones IFE (Table 1). The sensitivity of an increased $\kappa$-SFLC for the detection of monoclonal proteins by IFE was $82 \%$, while 
Table 1 Sensitivity and specificity of increased $\kappa-S F L C$ and increased SFLC-ratio for the detection of monoclonal proteins by IFE involving the $\kappa$ light chain (intact immunoglobulin or FLC), increased $\lambda$-SFLC and decreased SFLC-ratio for the detection of all for the detection of monoclonal proteins by IFE involving the $\lambda$ light chain (intact immunoglobulin or FLC) and combined abnormal SFLC-ratio $(<0.26$ or $>1.65)$ for the detection of any monoclonal protein (intact or FLC).

\begin{tabular}{lllll}
\hline & Sensitivity & Specificity & $\begin{array}{l}\text { Positive predictive } \\
\text { value }\end{array}$ & $\begin{array}{l}\text { Negative predictive } \\
\text { value }\end{array}$ \\
\hline $\mathrm{K}-\mathrm{SFLC}>19.4 \mathrm{mg} / \mathrm{L}$ & 0.82 & 0.48 & 0.24 & 0.93 \\
$\lambda-\mathrm{SFLC}>26.3 \mathrm{mg} / \mathrm{L}$ & 0.58 & 0.66 & 0.22 & 0.91 \\
$\kappa / \lambda$-ratio $>1.65$ & 0.52 & 0.94 & 0.65 & 0.91 \\
$\kappa / \lambda$-ratio $<0.26$ & 0.31 & 0.99 & 0.88 & 0.9 \\
Combined abnormal ratio & 0.41 & 0.96 & 0.79 & 0.9 \\
$<0.26$ and $>1.65$ & & & & \\
\hline
\end{tabular}

SFLC, serum free light chain; IFE, immunofixation; FLC, free light chain.

sensitivity of increased $\lambda$-SFLC, decreased or increased ratio and abnormal $\lambda$-SFLC ratio were $58 \%, 31 \%$, $52 \%$ and $41 \%$, respectively. The specificity of an abnormal SFLC-ratio was $96 \%, 48 \%$ for increased $\kappa-$ SFLC and $66 \%$ for increased $\lambda$-SFLC in the detection of monoclonal proteins by IFE. All $\kappa$ - and $\lambda$-light chain diseases were detected with the SFLC immunoassay (Table 2). The positive predictive value (PPV) for the detection of PCD was $79 \%$ for an abnormal ratio. Abnormal SFLC concentrations occurred in patients with oligoclonal IFE results (Table 2) and abnormal ratios were detected in eight patients. Abnormal SFLC concentrations were found in patients with intact, monoclonal $\kappa$ - and $\lambda$ - immunoglobulins (Table 2). Overall, 51 of 215 patients were positive by IFE only. Among the 426 patients negative by IFE, 52\% and $34 \%$ had increased $\kappa$ and/ or $\lambda$ SFLC concentration, respectively, but with a normal SFLC-ratio.

\section{Patients with abnormal SFLC-ratios and negative IFE}

Eighteen patients with abnormal SFLC-ratios but negative monospecific and Bence Jones IFE were detect- ed and classified as equivocal (Figure 1, Table 3). Two samples with an abnormal ratio but normal individual SFLC were excluded because the patient history was not consistent with monoclonal gammopathy. One of these patients was admitted for psychiatric disease, the other was admitted for diabetes mellitus and renal insufficiency. Concentrations of SFLC were, in most cases, below the detection limit of the Bence Jones IFE (150 mg/L). Therefore, monoclonality could not be proven. Four of the patients had SFLC-ratios $<0.26$, indicating a shift towards $\lambda$-SFLC, while the other ratios were $>1.65$ indicating a shift towards $\kappa$-SFLC. Nine of these patients suffered from haematological disorders including chronic lymphatic leukaemia (CLL) and other lymphomas. Other patients were diagnosed with autoimmune disorders including rheumatic arthritis and systemic lupuserythematosus, inflammatory processes and non-haematological tumours. In one patient (patient 14), increased SFLC resulted in bone marrow biopsy, which was negative. In four patients, increased plasma creatinine concentrations were detected and two patients were diagnosed with renal insufficiency.

One patient (patient 16, Table 3) presented with renal insufficiency attributed to type 2 diabetes mel-

Table $2 \mathrm{k}-, \lambda$-SFLC concentrations and SFLC-ratios in patients with IFE confirmed by monoclonal gammopathy (intact immunoglobulin or FLC) and patients with oligoclonal pattern ${ }^{a}$ ( 3 or more low-level bands) by IFE.

\begin{tabular}{|c|c|c|c|c|}
\hline IFE result & No. & $\begin{array}{l}\text { No. of abnormal } \\
\kappa, \%\end{array}$ & $\begin{array}{l}\text { No. of abnormal } \\
\text { ratio, \% }\end{array}$ & \\
\hline $\lg$ g-к & 79 & $62(78)$ & $39(49)$ & \\
\hline $\lg A-\kappa$ & 13 & $12(92)$ & $10(77)$ & \\
\hline IgM-к & 18 & $15(83)$ & $5(28)$ & \\
\hline \multirow[t]{2}{*}{$\kappa$-Light chain } & 9 & $9(100)$ & $9(100)$ & \\
\hline & & No. of abnormal $\lambda, \%$ & No. of abnormal ratio, $\%$ & \\
\hline $\lg G-\lambda$ & 68 & $36(53)$ & $14(21)$ & \\
\hline $\lg A-\lambda$ & 9 & $5(56)$ & $3(33)$ & \\
\hline $\lg M-\lambda$ & 6 & $4(67)$ & $1(17)$ & \\
\hline $\lg \mathrm{D}-\lambda$ & 3 & $3(100)$ & $3(100)$ & \\
\hline \multirow[t]{2}{*}{$\lambda$-Light chain } & 9 & $9(100)$ & $9(100)$ & \\
\hline & & No. of abnormal к, \% & No. of abnormal $\lambda, \%$ & No. of abnormal ratio, $\%$ \\
\hline Negative & 426 & $221(52)$ & $146(34)$ & $20(5)$ \\
\hline Oligoclonal $^{\mathrm{a}}$ & 50 & $38(76)$ & $29(58)$ & $8(16)$ \\
\hline $\begin{array}{l}\lg A \text { (non-reactive } \\
\text { with } \kappa \text { or } \lambda \text { ) }\end{array}$ & 1 & 1 & 0 & 0 \\
\hline
\end{tabular}

SFLC, serum free light chain; IFE, immunofixation; FLC, free light chain. 


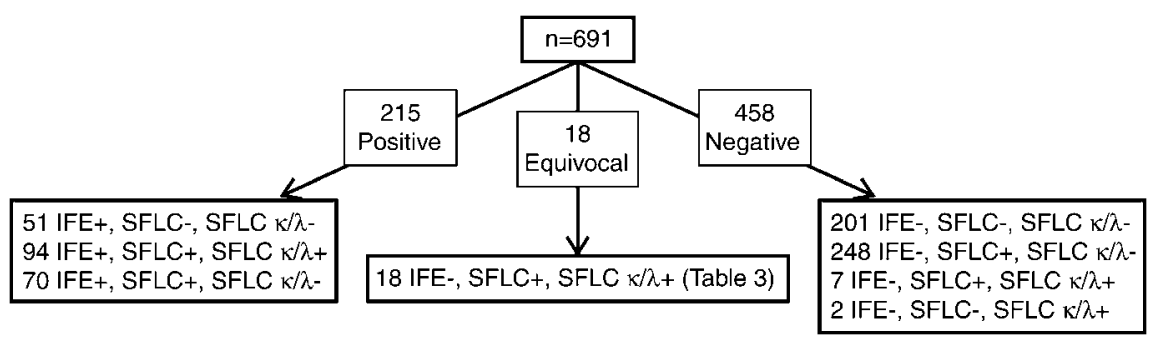

Figure 1 Flow chart of the results of the plasma cell dyscrasias (PCD) screening programme in serum including immunofixation (IFE) (monospecific and Bence Jones) and measurement of serum free light chain (SFLC) in 691 patients.

IFE + indicates that IFE was positive and a monoclonal protein was detected, SFLC + indicates that $\kappa$ - and/or $\lambda$-SLFC were abnormal, SFLC $\mathrm{k} / \lambda+$ indicates that the SFLC-ratio was abnormal.

Table 3 Summary of SFLC-concentrations, SFLC-ratio, creatinine concentration in serum and clinical diagnosis in 18 patients with negative monospecific and negative Bence Jones IFE, but abnormal SFLC-ratios $(<0.26$ or $>1.65)$.

\begin{tabular}{|c|c|c|c|c|c|c|}
\hline $\begin{array}{l}\text { Patient } \\
\text { no. }\end{array}$ & $\begin{array}{l}\kappa-S F L C, \\
\mathrm{mg} / \mathrm{L}\end{array}$ & $\begin{array}{l}\lambda-S F L C \\
\mathrm{mg} / \mathrm{L}\end{array}$ & $\kappa / \lambda$-ratio & $\begin{array}{l}\text { Monospecific } \\
\text { and Bence Jones } \\
\text { IFE result }\end{array}$ & $\begin{array}{l}\text { Clinical diagnosis (bone } \\
\text { marrow biopsy was } \\
\text { performed if indicated) }\end{array}$ & $\begin{array}{l}\text { Creatinine, } \mathrm{mol} / \mathrm{L} \\
\text { (individual reference } \\
\text { range) }\end{array}$ \\
\hline 1 & $<10$ & 164 & $<0.06$ & Negative & CLL & $112(72-127)$ \\
\hline 2 & $<10$ & 58.3 & $<0.17$ & Negative & CLL & $109(72-127)$ \\
\hline 3 & $<10$ & 43.4 & $<0.23$ & Negative & CLL & $138(72-127)$ \\
\hline 4 & 13 & 52.7 & 0.25 & Negative & Systemic lupus erythematosus & $61(58-96)$ \\
\hline 5 & 54.3 & 32.4 & 1.68 & Negative & $\begin{array}{l}\text { Rheumatoid arthritis, renal } \\
\text { insufficiency }\end{array}$ & $157(72-127)$ \\
\hline 6 & 34.1 & 19.8 & 1.72 & Negative & $\begin{array}{l}\text { Renal insufficiency, } \\
\text { inflammatory process }\end{array}$ & $319(72-127)$ \\
\hline 7 & 23.8 & 12 & 1.98 & Negative & Unknown & $97(72-127)$ \\
\hline 8 & 26.9 & 13.4 & 2.01 & Negative & Epileptic seizure & $93(58-96)$ \\
\hline 9 & 20.9 & $<10$ & $>2.09$ & Negative & CLL & $97(72-127)$ \\
\hline 10 & 21.2 & $<10$ & $>2.12$ & Negative & CLL & $99(72-127)$ \\
\hline 11 & 26.2 & 10.5 & 2.50 & Negative & Diffuse large B-cell-lymphoma & $147(58-96)$ \\
\hline 12 & 25.1 & $<10$ & $>2.51$ & Negative & Prostate cancer & $67(72-127)$ \\
\hline 13 & 26.5 & $<10$ & $>2.65$ & Negative & Angiosarcoma. Diabetes mellitus & $121(72-127)$ \\
\hline 14 & 79.5 & $<10$ & $>3.02$ & Negative & $\begin{array}{l}\text { LCMM suspected (Negative bone } \\
\text { marrow biopsy) }\end{array}$ & $87(72-127)$ \\
\hline 15 & 137 & $<10$ & $>13.70$ & Negative & Mantle cell lymphoma & $83(72-127)$ \\
\hline 16 & 659 & 37.2 & 17.72 & Negative & $\begin{array}{l}\text { Amyloidosis (negative bone marrow } \\
\text { biopsy but positive kidney biopsy) }\end{array}$ & $436(58-96)$ \\
\hline 17 & 753 & 12.1 & 62.23 & Negative & $\begin{array}{l}\text { к-Light chain myeloma (positive } \\
\text { bone marrow biopsy) }\end{array}$ & $104(72-127)$ \\
\hline 18 & 4830 & 47.7 & 101.26 & Negative & $\begin{array}{l}\kappa \text {-Light chain myeloma (positive } \\
\text { bone marrow biopsy) }\end{array}$ & $686(58-96)$ \\
\hline
\end{tabular}

If bone marrow biopsies were performed they are indicated in the clinical diagnosis section. Patients with later proven light chain disease are in bold font. SFLC, serum free light chain; IFE, immunofixation; CLL, chronic lymphatic leukaemia; LCMM, light-chain multiple myeloma.

litus and amyloidosis was suspected following renal biopsy. Bone marrow biopsy revealed no abnormalities. One patient (patient 18, Table 3) presented with nausea, weight loss, exhaustion and a plasma creatinine of $914 \mu \mathrm{mol} / \mathrm{L}$, indicative of renal insufficiency. A bone marrow biopsy following the result of monoclonal screening confirmed the diagnosis of LCMM. One patient (patient 17, Table 3) presented with weight loss, exhaustion, bone pain and fever in a peripheral hospital and was transferred for further diagnostic procedures. Bone marrow biopsy confirmed the diagnosis of LCMM. Serum and urine from patients 16 and 18 was subjected to further investigations. Serum was found negative by a second Bence Jones IFE (Titan Gel Immunofixation, Helena, Beaumont, TX, USA). In addition, Bence Jones IFE from urine was negative, although increased concentrations of $\kappa$-SFLC were detected by the "Freelite" assay. Serum and urine from patient 17 was not investigated further.

\section{Increased $\kappa-/ \lambda$-SFLC concentrations $>150 \mathrm{mg} / \mathrm{L}$ in patients negative by Bence Jones IFE}

Eleven patients with $\kappa$ and three patients with $\lambda$ light chain concentrations above $150 \mathrm{mg} / \mathrm{L}$ were negative by Bence Jones IFE, although the SFLC-ratio indicated the presence of monoclonal Bence Jones protein (Table 4). This group also included patients 16-18 described above. All other patients had monoclonal, intact immunoglobulin using monospecific IFE. In most cases, the other light chain was within the nor- 
Table 4 Summary of SFLC-concentrations, SFLC-ratio, result of monovalent IFE and clinical diagnosis from 11 patients with negative Bence Jones IFE but either $\kappa$ - or $\lambda$-SFLC $>150 \mathrm{mg} / \mathrm{L}$ (theoretical cut-off of Bence Jones IFE).

\begin{tabular}{|c|c|c|c|c|c|c|}
\hline $\begin{array}{l}\text { Patient } \\
\text { no. }\end{array}$ & $\begin{array}{l}\text { к-SFLC, } \\
\mathrm{mg} / \mathrm{L}\end{array}$ & $\begin{array}{l}\lambda-S F L C \\
\mathrm{mg} / \mathrm{L}\end{array}$ & Ratio & $\begin{array}{l}\text { Monospecific } \\
\text { IFE result }\end{array}$ & $\begin{array}{l}\text { Bence-Jones- } \\
\text { IFE result }\end{array}$ & Clinical diagnosis \\
\hline 19 & 1960 & $<10$ & $>196$ & $\lg A-\kappa$ & Negative & IgA-к myeloma \\
\hline 20 & 1370 & $<10$ & $>137$ & $\lg$-к & Negative & IgG-к myeloma \\
\hline 21 & 740 & 14.1 & 52.5 & $\operatorname{lgG}-\kappa$ & Negative & IgG-к myeloma \\
\hline 22 & 592 & 24.3 & 24.4 & $\lg G-\kappa$ & Negative & $\begin{array}{l}\text { Acute cardiac decompensation } \\
\text { (no further PCD work-up, follow-up lost) }\end{array}$ \\
\hline 23 & 413 & 22 & 18.8 & $\lg \mathrm{g}-\kappa$ & Negative & IgG-к myeloma \\
\hline 24 & 400 & 18.3 & 21.9 & $\lg G-\kappa$ & Negative & IgG-к myeloma \\
\hline 25 & 173 & 46.6 & 3.7 & $\lg G-\kappa$ & Negative & $\begin{array}{l}\text { Negative bone marrow biopsy } 2 \text { years } \\
\text { earlier, IgG-к myeloma } 2 \text { years later }\end{array}$ \\
\hline 26 & 160 & 46.8 & 3.4 & $\lg M-\lambda$ & Negative & $\begin{array}{l}\text { Acute cardiac decompensation } \\
\text { (no further PCD work-up, follow-up lost) }\end{array}$ \\
\hline 27 & $<10$ & 2440 & $<0.004$ & $\lg A-\lambda$ & Negative & IgG- $\lambda$ myeloma \\
\hline 28 & $<10$ & 371 & $<0.027$ & $\lg G-\lambda$ & Negative & $\lg \mathrm{g}-\lambda$ myeloma \\
\hline 29 & 18.4 & 293 & 0.06 & $\lg G-\lambda$ & Negative & $\lg \mathrm{g}-\lambda$ myeloma \\
\hline
\end{tabular}

Patients 16-18 from Table 3 (SFLC concentrations $>150 \mathrm{mg} / \mathrm{L}$ and negative by Bence Jones IFE) are not repeatedly listed. SFLC, serum free light chain; IFE, immunofixation; PCD, plasma cell dyscrasias.

mal range. In two patients, detection of the monoclonal protein did not result in a further work-up were lost to follow-up.

\section{Performance of a modified serum only screening procedure}

The performance of a modified work-up, similar to that recently suggested by Piehler et al. (11), was analysed retrospectively. Similar to the procedure described, pentavalent IFE would have been performed only if abnormalities were detected by SPE (pronounced hypogammaglobulinaemia, suspected M-protein band) or if $\kappa-, \lambda$-SFLC concentrations or the SFLC-ratio were abnormal. Using this approach, 180 fewer pentavalent IFEs would have been performed (26\%) (Figure 2).

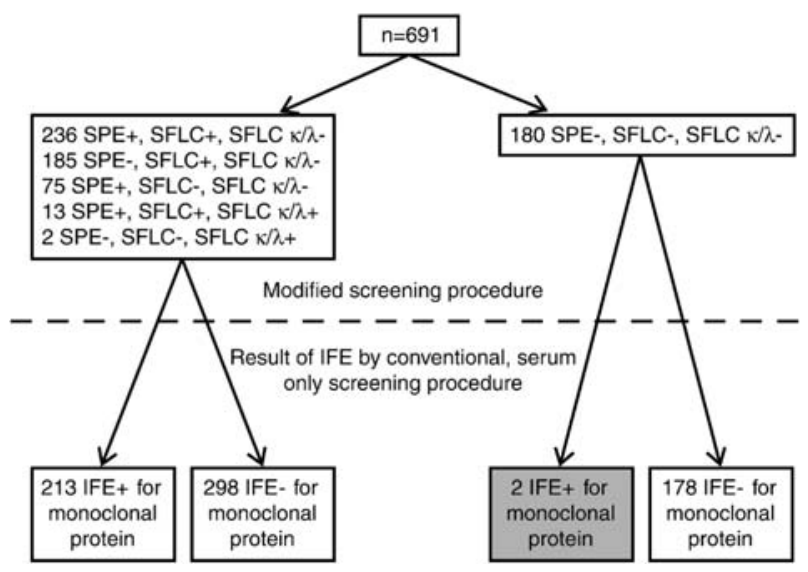

Figure 2 Flow chart breaking down the results of the modified screening procedure in terms of SPE + (pronounced hypogammaglobulinaemia, suspected monoclonal band) and/or SFLC + [increased SFLC concentrations (one or both)] and/or SFLC $\kappa / \lambda+$ (abnormal $\kappa-/ \lambda$-SFLC-ratio).

IFE results from all patients are listed in the lower part and separated by a dashed line.
However, two of these patients and one other patient, identified as having no abnormality on SPE, normal SFLC concentrations and ratio, were found to have a monoclonal protein by IFE. All monoclonal bands that were detected were of weak intensity, but clearly visible.

\section{Discussion}

Screening for monoclonal gammopathies in the routine diagnostic laboratory did, until recently, include analysis of serum and urine $(1,2)$. Following the introduction of a commercially available automated assay for the detection and quantitation of SFLC, a more simplified strategy, avoiding the frequently forgotten, time-consuming collection of urine and work-up has been evaluated $(7,10-12,16)$. While intact monoclonal immunoglobulins are usually detected by the presence of an M-protein band on SPE, increased concentrations of SFLC and/or abnormal ratios suggests the presence of monoclonal light-chain disease. When intact monoclonal proteins are present in serum, SFLC may be produced in excess, accompanying heavy-chain bound FLC of the same type. The sensitivity and specificity of increased $\kappa$ - and $\lambda$-SFLC for the detection of monoclonal proteins was lower than reported previously (8), although the percentage of sera with abnormal SFLC-ratios among the individuals with monoclonal gammopathies was comparable to the percentage quoted in another study (8). The PPV was moderately higher for ratios $<0.26$, and clearly higher for ratios $>1.65$ compared to that reported by Hill et al. (7). For the combined abnormal ratio $(<0.26$; $>1.65)$ results were comparable to that reported by Vermeersch et al. (16) in similar hospital populations. Differences in assay performance for the prediction of positive IFE (intact immunoglobulin or FLC) may be due to differences in patient populations that are analysed because specificity of any assay will 
increase if pre-test probability increases, as is the case when using serum from patients with IIMM only.

All LCMM where detected using the "Freelite" assay. All patients with IgD- $\lambda$ IIMM had very high SFLC concentrations, a fact also described by Mead et al. (18).

In general, the clinical use of SFLC quantitation in the work-up of PCD largely depends on careful preselection of patients. If the pre-test probability is low, a situation often occurring in unselected patient populations, increased FLC concentrations in individuals should be interpreted with care because several clinical conditions may cause this finding $(17,19-21)$. If no other symptoms point toward the diagnosis of a PCD, performing a time-consuming, onerous PCD work-up might not be reasonable. However, abnormal SFLC-ratios are very specific for monoclonal gammopathies, and a diagnostic follow-up including additional diagnostic investigations should be considered.

Among the patients with abnormal SFLC-ratios and negative Bence Jones IFE, haematological disorders dominated with CLL being the most frequent diagnosis. These conditions have been correlated with increased SFLC concentrations (22-24) and it appears to be a common feature associated with haematological disorders. Among the remaining patients, inflammation and kidney disease were notable and these two conditions have been associated with increased SFLC concentrations $(17,19-21)$. In the case of patients with kidney insufficiency, wider reference ranges have been recently suggested (17). In our study, four patients received further diagnostic workup due to an increased SFLC ratio despite a negative IFE, resulting in the detection of PCD in three cases. When interpreting abnormal SFLC-ratios, one should consider along with concentrations of the SFLC, renal function, presence of inflammatory disease and the IFE result. Also, imprecision of the assay needs to be considered since the calculation of the ratio depends on the imprecision of two parameters. Patients with minimally elevated or decreased ratios may have normal ratios when samples are assayed repeatedly, or assayed with different reagent lots or with a different analyser $(20,25)$. Considering these limitations, the SFLC-ratio may provide a very specific parameter for the detection of PCD in IFE-negative patients. However, the patient population used in this study was too small to derive a cut-off ratio, which would prompt further diagnostic procedures, such as bone marrow biopsy or bone scan.

In 14 patients, markedly increased concentrations of either $\kappa$ - or $\lambda$-SFLC were measured, without detecting monoclonal bands by Bence Jones IFE. Increased SFLC concentrations with negative IFE primarily affected patients with increased $\kappa-S F L C$. Most of these patients presented with a monoclonal, intact immunoglobulin using monospecific IFE, a condition frequently accompanied by excessive SFLC production. Overestimation of SFLC concentrations is a commonly described problem when measuring SFLC in serum (20). Therefore, some of the Bence Jones proteins detected in these patients might not be detectable by
IFE because the "true" SFLC concentration was lower than that measured in the SFLC assay. In some patients with very high SFLC concentrations, it is more likely that the antiserum did not bind the respective light chain or that polymerisation of FLC (26) resulted in a negative IFE. However, monitoring SFLC in patients with intact immunoglobulins and increased SFLC might be important because renal involvement is detected in a high percentage of patients with multiple myeloma (27), which may be caused by the light chain component of the disease. This is especially underscored by the fact that renal involvement was found in $100 \%$ of all patients with monoclonal IgD-protein. This study and another found monoclonal IgD-protein associated with very high SFLC concentrations (19). Bence Jones IFE was negative and SFLC concentrations were high in two patients later diagnosed with LCMM (Table 3, patients 17 and 18) and one patient with $A L$ (Table 3, patient 16). In the patients with LCMM, measurement of SFLC provided a useful complement for the work-up of PCD because, compared to other diagnostic procedures, it is less expensive and less onerous for the patient. In the patient with $A L$, it supported the diagnosis that was suspected following kidney biopsy. However, in patients with suspected $A L$, analysis of urine should always be included because of its higher sensitivity (15).

Recently, a modified work-up has been proposed and we retrospectively tested the performance of this work-up in our patient population. In contrast to Piehler et al. (11), SFLC were assayed in all patient samples because information from clinicians and from the hospital information system are impractical to obtain and might be inaccurate. Using this setting, three patients were missed who were diagnosed with intact monoclonal protein using IFE. We showed that not all patients with intact monoclonal proteins in serum produce SFLC in excess resulting in normal or almost normal SFLC concentrations and a normal ratio. In addition, monoclonal peaks of the IgM-type may be covered by the IgG-fraction in the $\gamma$ globulin fraction and peaks of the IgA-type may be covered by the $\beta$ globulin fraction in the SPE. Also, peaks of the IgG-type may not be discovered by SPE. In contrast to the result by Piehler et al. (11), three patients with intact monoclonal immunoglobulins by IFE were not detected in the modified screening procedure. Although the clinical significance of these findings has been questioned $(7,12)$, insufficient information on these patients was available to the laboratory to determine the clinical relevance. The laboratory should supply all available information with careful interpretation and consultation with the haematologist is recommended to decide on further laboratory and clinical investigations. If, for example, MGUS is diagnosed based on these results, there is an increased risk for the developing malignancy and these patients should be monitored regularly (28).

If IFE of serum is omitted from the screening procedure, the sensitivity of screening will decrease because cases with normal SFLC concentrations and 
ratios the detection of intact monoclonal immunoglobulins relies solely on SPE, and monoclonal proteins may not be visible in all cases. Therefore, IFE should be a part of the screening procedure for monoclonal proteins.

Limitations of this study were that Bence Jones IFE in urine was not part of the general screening programme. Although there is evidence that screening serum only is sufficient to detect all patients with clinically relevant PCD, screening of serum and urine is still considered the gold standard and therefore not all patients with PCD might have been detected.

\section{References}

1. Smith A, Wisloff F, Samson D. Guidelines on the diagnosis and management of multiple myeloma 2005. Br J Haematol 2006;132:410-51.

2. Keren DF. Procedures for the evaluation of monoclonal immunoglobulins. Arch Pathol Lab Med 1999;123:12632.

3. Nakano T, Miyazaki S, Takahashi H, Matsumori A, Maruyama $T$, Komoda $T$, et al. Immunochemical quantification of free immunoglobulin light chains from an analytical perspective. Clin Chem Lab Med 2006;44: 522-32.

4. Bradwell AR, Carr-Smith HD, Mead GP, Tang LX, Showell PJ, Drayson MT, et al. Highly sensitive, automated immunoassay for immunoglobulin free light chains in serum and urine. Clin Chem 2001;47:673-80.

5. Criteria for the classification of monoclonal gammopathies, multiple myeloma and related disorders: a report of the International Myeloma Working Group. $\mathrm{Br} \mathrm{J}$ Haematol 2003;121:749-57.

6. Guidelines on the diagnosis and management of $\mathrm{AL}$ amyloidosis. Br J Haematol 2004;125:681-700.

7. Hill PG, Forsyth JM, Rai B, Mayne S. Serum free light chains: an alternative to the urine Bence Jones proteins screening test for monoclonal gammopathies. Clin Chem 2006;52:1743-8.

8. Jaskowski TD, Litwin CM, Hill HR. Detection of kappa and lambda light chain monoclonal proteins in human serum: automated immunoassay versus immunofixation electrophoresis. Clin Vaccine Immunol 2006;13:27780.

9. Nowrousian MR, Brandhorst D, Sammet C, Kellert M, Daniels $R$, Schuett $P$, et al. Serum free light chain analysis and urine immunofixation electrophoresis in patients with multiple myeloma. Clin Cancer Res 2005; 11:8706-14.

10. Beetham R, Wassell J, Wallage MJ, Whiteway AJ, James JA. Can serum free light chains replace urine electrophoresis in the detection of monoclonal gammopathies? Ann Clin Biochem 2007;44:516-22.

11. Piehler AP, Gulbrandsen N, Kierulf P, Urdal P. Quantitation of serum free light chains in combination with protein electrophoresis and clinical information for diagnosing multiple myeloma in a general hospital population. Clin Chem 2008;54:1823-30.

12. Katzmann JA, Dispenzieri A, Kyle RA, Snyder MR, Plevak $M F$, Larson DR, et al. Elimination of the need for urine studies in the screening algorithm for monoclonal gammopathies by using serum immunofixation and free light chain assays. Mayo Clin Proc 2006;81:1575-8.

13. Hofmann W, Garbrecht M, Bradwell AR, Guder WG. A new concept for detection of Bence Jones proteinuria in patients with monoclonal gammopathy. Clin Lab 2004; 50:181-5.

14. Harding SJ, Mead GP, Bradwell AR, Berard AM. Serum free light chain immunoassay as an adjunct to serum protein electrophoresis and immunofixation electrophoresis in the detection of multiple myeloma and other Bcell malignancies. Clin Chem Lab Med 2009;47:302-4.

15. Palladini G, Russo P, Bosoni T, Verga L, Sarais G, Lavatelli $F$, et al. Identification of amyloidogenic light chains requires the combination of serum-free light chain assay with immunofixation of serum and urine. Clin Chem 2009;55:499-504.

16. Vermeersch P, Van Hoovels L, Delforge M, Marien G, Bossuyt X. Diagnostic performance of serum free light chain measurement in patients suspected of a monoclonal B-cell disorder. Br J Haematol 2008;143:496-502.

17. Abadie JM, van Hoeven $\mathrm{KH}$, Wells JM. Are renal reference intervals required when screening for plasma cell disorders with serum free light chains and serum protein electrophoresis? Am J Clin Pathol 2009;131:166-71.

18. Mead GP, Carr-Smith HD, Drayson MT, Morgan GJ, Child JA, Bradwell AR. Serum free light chains for monitoring multiple myeloma. Br J Haematol 2004;126:34854

19. Hutchison CA, Harding S, Hewins P, Mead GP, Townsend J, Bradwell AR, et al. Quantitative assessment of serum and urinary polyclonal free light chains in patients with chronic kidney disease. Clin J Am Soc Nephrol 2008;3:1684-90.

20. Tate JR, Gill D, Cobcroft R, Hickman PE. Practical considerations for the measurement of free light chains in serum. Clin Chem 2003;49:1252-7.

21. Thio M, Blokhuis BR, Nijkamp FP, Redegeld FA. Free immunoglobulin light chains: a novel target in the therapy of inflammatory diseases. Trends Pharmacol Sci 2008;29:170-4.

22. Deegan MJ, Abraham JP, Sawdyk M, Van Slyck EJ. High incidence of monoclonal proteins in the serum and urine of chronic lymphocytic leukemia patients. Blood 1984;64: 1207-11.

23. Pascali E, Pezzoli A. Serum and urine monoclonal immunoglobulins in malignant non-Hodgkin's lymphoma. Acta Haematol 1986;75:193-8.

24. Martin W, Abraham R, Shanafelt T, Clark RJ, Bone N, Geyer SM, et al. Serum-free light chain - a new biomarker for patients with B-cell non-Hodgkin lymphoma and chronic lymphocytic leukemia. Transl Res 2007;149:231-5.

25. Tate JR, Mollee P, Dimeski G, Carter AC, Gill D. Analytical performance of serum free light-chain assay during monitoring of patients with monoclonal light-chain diseases. Clin Chim Acta 2007;376:30-6.

26. Solling K. Polymeric forms of free light chains in serum from normal individuals and from patients with renal diseases. Scand J Clin Lab Invest 1976;36:447-52.

27. Knudsen LM, Hippe E, Hjorth M, Holmberg E, Westin J. Renal function in newly diagnosed multiple myeloma a demographic study of 1353 patients. The Nordic MyeIoma Study Group. Eur J Haematol 1994;53:207-12.

28. Blade J, Rosinol L, Cibeira MT, de Larrea CF. Pathogenesis and progression of monoclonal gammopathy of undetermined significance. Leukemia 2008;22:1651-7. 